\title{
A New Tricyclic Undecose Nucleoside from Streptomyces scopuliridis RB72
}

\author{
Chun Whan Choi, Jung-Sup Choi, ${ }^{\dagger}$ Young Kwan Ko, ${ }^{\dagger}$ Chang-Jin Kim, ${ }^{\dagger}$ Young Ho Kim, ${ }^{\S}$ \\ Joa Sub Oh, Shi Yong Ryu, ${ }^{\dagger}$ and Gyu Hwan Yon ${ }^{\dagger, *}$

\begin{abstract}
Natural Products Research Institute, Gyeonggi Institute of Science \& Technology Promotion, Gyeonggi-do 443-766, Korea
${ }^{\dagger}$ Korea Research Institute of Chemical Technology, Daejeon 305-600, Korea. *E-mail: ghyon@krict.re.kr

${ }^{\star}$ Korea Research Institute of Bioscience and Biotechnology, Daejeon 305-333, Korea

${ }^{\S}$ College of Pharmacy, Chungnam National University, Daejeon 305-764, Korea
\end{abstract} \\ Received September 9, 2013, Accepted December 10, 2013
}

Key Words : Streptomyces Scopuliridis RB72, Herbicidins, Antimicrobial

Nucleoside antibiotics are fascinating compounds that show a variety of biological activities. ${ }^{1,2}$ Not only are they used as medicines, as lead compounds for the development of drugs, and as biological tools, but they are also important as total synthetic targets. ${ }^{3}$ The herbicidins of the A, B and F series of adenine nucleoside antibiotics, which have the same backbone structure, have been isolated from strains of Streptomyces. ${ }^{4-6}$ Herbicidins A and B efficiently inhibit the growth of Xanthomonas oryzae, which causes rice leaf blight, and they are also selectively toxic toward dicotyledon. These compounds have some interesting structural features: adenine is glycosylated at the $1 b$-position of an unusual sugar, undecose, which has a tricyclic furano-pyrano-pyran structure; there is an internal hemiketal linkage between the C-3'- and -7'-positions which forms a trans junction for a pyrano-pyran ring; and all of the substituents at the C-7'-, -8 '-, -9 '-, and $-10^{\prime}$-positions on the second pyranose are fixed in axial positions due to the tricyclic structure of the undecose. $^{7}$

The aim of this study was to investigate the chemical constituents and biological activities of Streptomyces sp. An antimicrobial compound producing strain was isolated from the woodlands in Daejeon, Korea, and identified as Streptomyces scopuliridis RB72 according to $16 \mathrm{~S}$ rRNA analysis. ${ }^{8}$ This strain was mass cultured in Bennet's medium ${ }^{9}$ with Diaion HP-20. A new nucleoside antibiotic constituent herbicidin $\mathrm{K}$ (1) and three known nucleoside antibiotic constituents, herbicidin A (2), herbicidin B (3) and herbicidin F (4), were isolated from the ethyl acetate extracts of Streptomyces scopuliridis RB72 (Fig. 1). The structures of 14 were elucidated by extensive MS and NMR spectroscopic methods including ${ }^{1} \mathrm{H} \mathrm{NMR},{ }^{13} \mathrm{C} \mathrm{NMR},{ }^{1} \mathrm{H}-{ }^{1} \mathrm{H}$ COSY, HMQC, HMBC and NOESY.

Herbicidin $\mathrm{K}(\mathbf{1})$, an amorphous powder $[\alpha]_{\mathrm{D}}^{20}:+0.13$ (C $0.2, \mathrm{CH}_{3} \mathrm{OH}$ ), has the molecular formula $\mathrm{C}_{22} \mathrm{H}_{27} \mathrm{~N}_{5} \mathrm{O}_{10}$, deduced by a high-resolution electrosprayionization time-offlight mass spectrometry (HRESITOFMS) experiment (found at $m / z[\mathrm{M}+\mathrm{H}]^{+}$) 522.1849, calculated for $\mathrm{C}_{22} \mathrm{H}_{28} \mathrm{~N}_{5} \mathrm{O}_{10}$ 522.1836). Its physico-chemical properties such as UV maxima at $260 \mathrm{~nm}$, two singlets due to heteroaromatic protons at $\delta 7.8-8.3 \mathrm{ppm}$, a doublet due to one proton at $\delta 5.9-$ $6.2 \mathrm{ppm}$ corresponding to the chemical shift of anomeric

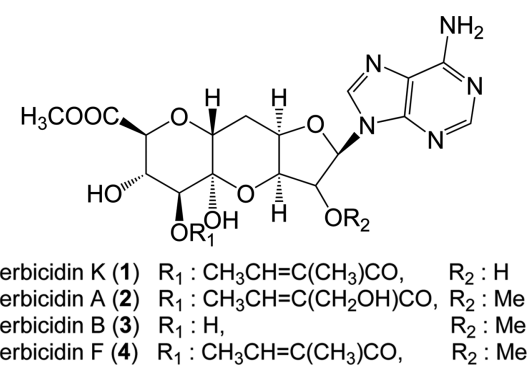

Figure 1. Structures of isolated herbicidins from Streptomyces scopuliridis RB72.

protons of usual nucleosides in the NMR spectra, and a fragment ion peak at 135 in the ESI mass spectrum suggested the presence of an adenine nucleoside moiety in the structures of 1. The ${ }^{1} \mathrm{H}$ NMR signals at $\delta 6.67$ (q, $J=7.2$ $\mathrm{Hz}), 1.85(3 \mathrm{H}, \mathrm{s})$, and $1.87(3 \mathrm{H}, \mathrm{d}, J=7.2 \mathrm{~Hz})$ together with those in the ${ }^{13} \mathrm{C}$ NMR spectrum at $\delta 167.3,141.9,128.5$, 15.2 and 12.4 suggested the presence of a tiglic acid moiety in the molecule. The ${ }^{13} \mathrm{C}$ NMR spectrum of 1 indicated the existence of methyl ester (52.8 and $171.4 \mathrm{ppm})$, methylene (26.8 ppm), one quaternary carbon $(93.4 \mathrm{ppm})$ and eight carbons attached to oxygen $(66.8,70.6,72.8,78.0,78.4$, 79.1, 82.6 and $91.2 \mathrm{ppm}$ ). Therefore, the basic skeleton of $\mathbf{1}$ was a tricyclic furano-pyrano-pyran skeleton. ${ }^{10}$ The ${ }^{1} \mathrm{H}$ and ${ }^{13} \mathrm{C}$ signals of $\mathbf{1}$ in the NMR spectrum were almost superimposable with those of herbicidin F (4) (Table 1), except for the methoxy group in $\mathbf{4}$ which was replaced by a hydroxy group in 1. All carbon-bond protons were assigned from the HMQC spectrum. The HMBC correlations observed between $\delta_{\mathrm{H}} 5.99(\mathrm{~d}, \mathrm{H}-1)$ and $\delta_{\mathrm{C}} 150.8$ and 140.7 (C-4 and 8), between $\delta_{\mathrm{H}} 4.99(\mathrm{~d}, \mathrm{H}-8)$ and $\delta_{\mathrm{C}} 167.3(\mathrm{C}-13)$, between $\delta \mathrm{H}$ $4.45(\mathrm{~s}, \mathrm{H}-10)$ and $\delta_{\mathrm{C}} 171.4(\mathrm{C}-11)$, and between $\delta_{\mathrm{H}} 6.67$ (q, $\mathrm{H}-15)$ and $\delta_{\mathrm{C}} 167.3(\mathrm{C}-13)$ indicated the adenine groups at $\mathrm{C}-1$, acetyl groups at $\mathrm{C}-10$, and the tiglic acid moiety at C-8. The relative configuration of compound 1 was determined on the basis of the NOESY spectrum (Figure 2). All proton signals and carbon signals of 1 were completely assigned by the aid of the two-dimensional NMR experiments of COSY, DEPT, HMQC and HMBC. To the best of our knowledge, 1 has never been isolated before from Streptomyces sp. or from any other natural resources. 
Table 1. ${ }^{1} \mathrm{H}$ - and ${ }^{13} \mathrm{C}-\mathrm{NMR}$ spectral data for compounds $\mathbf{1}$ and $\mathbf{4}$

\begin{tabular}{|c|c|c|c|c|c|c|}
\hline & \multicolumn{2}{|c|}{${ }^{1} \mathrm{H}(\mathbf{1})^{a}$} & \multicolumn{2}{|c|}{${ }^{1} \mathrm{H}(4)$} & \multicolumn{2}{|c|}{${ }^{13} \mathrm{C}(\mathbf{1}){ }^{13} \mathrm{C}(\mathbf{4})$} \\
\hline 1 & 5.99 & $\mathrm{~d}, 1.8$ & 6.05 & d, 1.9 & 91.2 & 91.9 \\
\hline 2 & 4.39 & br s & 4.07 & $\mathrm{~d}, 1.8$ & 82.6 & 88.9 \\
\hline 3 & 4.36 & $\mathrm{~d}, 1.8$ & 4.49 & $\mathrm{~d}, 2.2$ & 78.0 & 74.8 \\
\hline 4 & 4.50 & $\mathrm{~m}$ & 4.39 & $\mathrm{~m}$ & 79.1 & 79.1 \\
\hline 5 & $2.25 \& 2.29$ & $\mathrm{~m}$ & $2.25 \& 2.28$ & $\mathrm{~m}$ & 26.8 & 26.7 \\
\hline 6 & 4.51 & $\mathrm{q}, 5.4$ & 4.53 & $\mathrm{q}, 5.9$ & 66.8 & 66.7 \\
\hline 7 & & & & & 93.4 & 93.5 \\
\hline 8 & 4.99 & $\mathrm{~d}, 2.7$ & 5.01 & $\mathrm{~d}, 3.3$ & 72.8 & 72.0 \\
\hline 9 & 4.32 & $\mathrm{dd}, 1.3 \& 3.2$ & 4.32 & $\mathrm{dd}, 1.3 \& 3.2$ & 70.6 & 70.6 \\
\hline 10 & 4.45 & $\mathrm{~s}$ & 4.46 & $\mathrm{~s}$ & 78.4 & 78.4 \\
\hline 11 & & & & & 171.4 & 171.4 \\
\hline 12 & 3.60 & s & 3.61 & s & 52.8 & 52.8 \\
\hline 13 & & & & & 167.3 & 167.3 \\
\hline 14 & & & & & 128.5 & 128.6 \\
\hline 15 & 6.67 & $\mathrm{q}, 7.2$ & 6.71 & $\mathrm{q}, 7.1$ & 141.9 & 141.8 \\
\hline 16 & 1.87 & $\mathrm{~d}, 7.2$ & 1.90 & $\mathrm{~d}, 7.1$ & 15.2 & 15.2 \\
\hline 17 & 1.85 & $\mathrm{~s}$ & 1.87 & $\mathrm{~s}$ & 12.4 & 12.4 \\
\hline 18 & & & 3.41 & & & 58.5 \\
\hline $1^{\prime}$ & & & & & & \\
\hline $\mathbf{2}^{\prime}$ & 8.21 & $\mathrm{~s}$ & 8.21 & $\mathrm{~s}$ & 154.2 & 154.3 \\
\hline 3' & & & & & & \\
\hline $4^{\prime}$ & & & & & 150.8 & 150.6 \\
\hline $5^{\prime}$ & & & & & 119.9 & 119.9 \\
\hline $6^{\prime}$ & & & & & 157.6 & 157.6 \\
\hline $7^{\prime}$ & & & & & & \\
\hline $8^{\prime}$ & 7.97 & $\mathrm{~s}$ & 7.95 & $\mathrm{~s}$ & 140.7 & 140.6 \\
\hline $9^{\prime}$ & & & & & & \\
\hline
\end{tabular}

1 was measured in $\mathrm{CD}_{3} \mathrm{OD} .900 \mathrm{MHz}\left({ }^{1} \mathrm{H}\right)$ and $225 \mathrm{MHz}\left({ }^{13} \mathrm{C}\right), 4$ was measured in $\mathrm{CD}_{3} \mathrm{OD} .600 \mathrm{MHz}\left({ }^{1} \mathrm{H}\right)$ and $150 \mathrm{MHz}\left({ }^{13} \mathrm{C}\right) .{ }^{a} \mathrm{TMS}$ was used as the internal standard; chemical shifts are shown in the $\delta$ scale with the $J$ values in parentheses. br s: broad singlet; d: doublet; m: multiple.

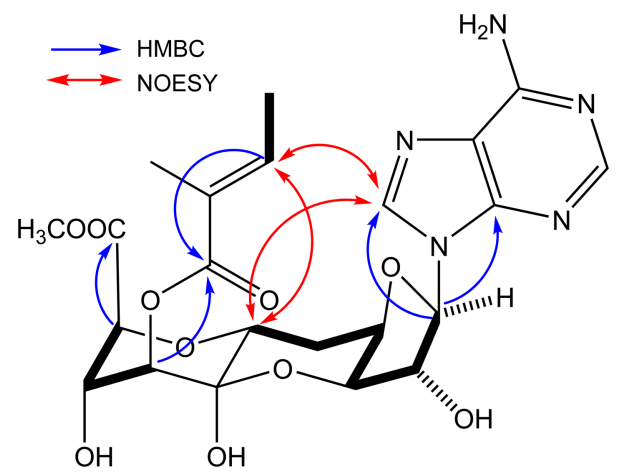

Figure 2. H-H COSY (bold lines) and Selected HMBC and NOESY (arrows) Correlations of $\mathbf{1}$.

\section{Experimental Section}

General Procedures. The high resolution electrospray ionization (HRESI) and electron impact (EI) mass spectra were obtained using a Q-Tof micro LC-MS/MS instrument (Waters, USA) and CP3800-1200L (Varian, USA) mass spectrometer, respectively. ${ }^{1} \mathrm{H}-\mathrm{NMR}$ (nuclear magnetic re- sonance) and ${ }^{13} \mathrm{C}-\mathrm{NMR}$ spectra were recorded on a Bruker (Rheinstetten, Germany) AM 300, AMX 500 and AMX 800 NMR spectrometer using TMS as an internal standard. Column chromatography was performed using a silica gel (Kieselgel 60, 70-230 mesh, Merck, Darmstadt, Germany) and Lichroprep RP-18 (40-63 mm, Merck). Thin layer chromatography (TLC) analysis was performed on Kieselgel $60 \mathrm{~F} 254$ plates (silica gel, $0.25 \mathrm{~mm}$, Merck) and spots were detected by examination with a UV lamp Spectroline Medel ENF-240 C/F (Spectronics Corporation, Westbury, NY) followed by the addition of $10 \% \mathrm{H}_{2} \mathrm{SO}_{4}$ reagent. Solvents and reagents were obtained from commercial sources and used without further purification. Unless otherwise noted, all chemicals were purchased from Sigma.

Fermentation, Extraction and Isolation. The Streptomyces scopuliridis RB72 was cultivated in Bennet's medium $80 \mathrm{~L},[160 \times 500 \mathrm{~mL}$ : yeast extrac $(0.5 \mathrm{~g})$, beef extract $(0.5$ g), N-Z amine type A (Sigma C0626, $1.0 \mathrm{~g}$ ), glucose (5.0 g), agar $(7.5 \mathrm{~g})$, distilled water $(0.5 \mathrm{~L})$, autoclave at $121{ }^{\circ} \mathrm{C}$ for 15 minutes] for 10 days at $27^{\circ} \mathrm{C}$ and then filtered with celite 545 (from Samchun Pure Chemical Co., Ltd). The filtrates were concentrated (121.4 g), passed through a diaion HP-20 (Adsorbent resin from Mitsubish Co., Ltd) column (15 cm $\times$ $50 \mathrm{~cm}$ ), and washed with $\mathrm{H}_{2} \mathrm{O}(5.0 \mathrm{~L})$ followed by $\mathrm{MeOH}$ $(5.0 \mathrm{~L})$. The $\mathrm{MeOH}$ extract was evaporated to dryness in vacuo and then the crude extract $(22.1 \mathrm{~g})$ was subjected to reversed phase C-18 (from Merck) flash chromatography (5 $\mathrm{cm} \times 50 \mathrm{~cm}$ ) using the solvent systems of $\mathrm{H}_{2} \mathrm{O}$ and $\mathrm{MeOH}$ with a $10 \%$ increase of $\mathrm{MeOH}$ to yield six fractions $(\mathrm{MeOH} /$ $\mathrm{H}_{2} \mathrm{O}=50 / 50,60 / 40,70 / 30,80 / 20,90 / 10$, and 100/0). The $60 \% \mathrm{MeOH}$ fraction was separated by reversed phase HPLC ( $25 \times 4.6 \mathrm{~mm}, 5 \mu \mathrm{m}, 2 \mathrm{~mL} / \mathrm{min}$ ) by eluting the $35 \% \mathrm{H}_{2} \mathrm{O}$ and $65 \% \mathrm{MeOH}$ solvents to produce a mixture at a retention time of $9 \mathrm{~min}$. For purification, the mixture was rechromatographed by using the $40 \% \mathrm{ACN}$ and $60 \% \mathrm{H}_{2} \mathrm{O}$ solvents to give compound $1(9 \mathrm{mg})$ and compound 2 (704 mg). Similarly, the $70 \% \mathrm{MeOH}$ fraction was separated with the $30 \% \mathrm{H}_{2} \mathrm{O}$ and $70 \% \mathrm{MeOH}$ solvents to yield compound 3 (54 $\mathrm{mg})$. Finally, compound 4 (14 mg) was isolated from the $80 \% \mathrm{MeOH}$ subfraction by using the $25 \% \mathrm{H}_{2} \mathrm{O}$ and $75 \%$ $\mathrm{MeOH}$ solvents.

Herbicidin K (1): An amorphous powder $[\alpha]_{\mathrm{D}}^{20}:+0.13$ (C 0.2, $\mathrm{CH}_{3} \mathrm{OH}$ ), has the molecular formula $\mathrm{C}_{22} \mathrm{H}_{27} \mathrm{~N}_{5} \mathrm{O}_{10}$ deduced by a high-resolution electrosprayionization time-offlight mass spectrometry (HRESITOFMS) experiment (found at $\mathrm{m} / z[\mathrm{M}+\mathrm{H}]^{+}$) 522.1849, calculated for $\mathrm{C}_{22} \mathrm{H}_{28} \mathrm{~N}_{5} \mathrm{O}_{10}$ 522.1836). ${ }^{1} \mathrm{H}$ and ${ }^{13} \mathrm{C}-\mathrm{NMR}$ spectra data are presented in Table 1.

Acknowledgments. This study was supported by the Rural Development Administration, Republic of Korea (PJ0068201002) and by the KRICT's own project (KK1304-B0).

\section{References}

1. Isono, K. J. Antibiot. 1988, 41, 1711. 
2. Isono, K. Pharmacol. Ther. 1991, 52, 269.

3. Hager, D.; Mayer, P.; Paulitz, C.; Tiebes, J.; Trauner, D. Angew. Chem. Int. Ed. 2012, 51, 6525.

4. Arai, M.; Naneishi, T.; Kitahara, N.; Enokita, R.; Kawakubo, K.; Kondo, Y. J. Antibiot. 1976, 30, 863.

5. Haneishi, T.; Terahara, A.; Kayamori, H.; Yabe, J.; Arai, M. J. Antibiot. 1976, 29, 870.

6. Takiguchi, Y.; Yoshikawa, H.; Terahara, A.; Torikata, A.; Terao, M. J. Antibiot. 1979, 32, 857.
7. Ichikawa, S.; Shuto, S.; Matsuda, A. J. Am. Chem. Soc. 1999, 121, 10270.

8. Lee, B.; Kim, J. D.; Kim, Y. S.; Ko, Y. K.; Yon, G. H.; Kim, C. J.; Koo, S. J.; Choi, J. S. Weed Turf. Sci. 2013, 2, 38.

9. Hesseltine, C. W.; Benedict, R. G.; Pridham, T. G. Useful criteria for species differentiation in the genus Streptomyces. Ann. N. Y. Acad. Sci. 1954, 60, 136.

10. Terahara, A.; Haneishi, T.; Arai, M.; Hata, T.; Kuwano, H.; Tamura, C. J. Antibiot. 1982, 35, 1711. 